\title{
Erratum to: Enhanced antibacterial effect of silver nanoparticles obtained by electrochemical synthesis in poly(amide-hydroxyurethane) media
}

\author{
Marius Stefan • Lucian Hritcu • Marius Mihasan • \\ Daniela Pricop • Irina Gostin • Romeo-Iulian Olariu • \\ Simona Dunca $\cdot$ Viorel Melnig
}

Published online: 14 June 2011

(C) Springer Science+Business Media, LLC 2011

Erratum to: J Mater Sci: Mater Med (2011)

$$
\begin{aligned}
& \text { 22(4):789-796 } \\
& \text { DOI } 10.1007 / \mathrm{s} 10856-011-4281-z
\end{aligned}
$$

The original version of this article unfortunately contained a mistake. The authors names were presented as family names instead of given names. The correct names are given above.

The online version of the original article can be found under doi:10.1007/s10856-011-4281-z.

M. Stefan $(\bowtie)$ - L. Hritcu · M. Mihasan · I. Gostin · S. Dunca Faculty of Biology, "Alexandru Ioan Cuza"' University, Iasi, Romania

e-mail: stefanm@uaic.ro

D. Pricop · V. Melnig

Faculty of Physics, COMB Laboratory, "Alexandru Ioan Cuza"

University, Iasi, Romania

\section{R.-I. Olariu}

Faculty of Chemistry, “Alexandru Ioan Cuza” University,

Iasi, Romania 